\title{
Identifikasi Ekstasi/MDMA Menggunakan Analisis Tes Warna dan Gas Chromatography-Mass Spectrometry (GCMS)
}

\author{
Yunita Suci Rahayu ${ }^{1}$, Yayuk Astuti ${ }^{1, *}$, Eko Fery Prasetya ${ }^{2}$ \\ ${ }^{1}$ Departemen Kimia, Fakultas Sains dan Matematika, Universitas Diponegoro, Semarang, Jawa Tengah \\ ${ }^{2}$ Bidang Laboratorium Forensik POLDA JATENG, Semarang, Jawa Tengah \\ *email korespondensi: yayuk.astuti@live.undip.ac.id
}

Received : 11 April 2020; Revised : 11 April 2020; Accepted : 2 Oktober 2020; Published : 14 Oktober 2020

\begin{abstract}
ABSTRAK
MDMA (3,4-Methilendioxymethamphetamine) atau sering dikenal ekstasi yaitu senyawa turunan amfetamin yang dapat menyebabkan rasa senang berlebihan dan biasanya banyak digunakan pada festival musik dansa atau diskotik. Penggunaan MDMA dapat memepengaruhi resiko kesehatan yang serius diantaranya dalam jangka pendek menyebabkan hipertermia, kejang, aritmia, hiponatremia, rhabdomiolisis dan kerusakan jangka panjang pada sistem saraf pusat. Salah satu metode untuk mengidentifikasi adanya senyawa MDMA yaitu menggunakan tes warna dan GCMS "Gas Chromatography-Mass Spectrometry". Uji tes warna merupakan uji screening untuk mengatahui ada tidaknya senyawa MDMA dalam sampel dengan menggunakan reagen marquis. Sedangkan GCMS yaitu instrumen yang dapat digunakan untuk mengetahui kandungan suatu senyawa dalam sampel dengan membandingkan waktu retensi antara senyawa yang belum diketahui dengan waktu retensi referensi. Pada penelitian ini, penulis melakukan identifikasi barang bukti tablet menggunakan analisis tes warna dan GCMS. Hasil yang diperoleh pada uji tes warna yaitu terjadi perubahan warna dari merah menjadi hitam. Kemudian dilakukan uji konfirmatif menggunakan metode GCMS. Hasil yang diperoleh yaitu pada spektra GC terdapat dua puncak yang menonjol yaitu MDMA dan kafein dengan waktu retensi berturut-turut yaitu 10,875 menit dan 13,341 menit. Hasil ini sesuai dengan Library W10N11. Berdasarkan hasil pengujian tersebut, dapat disimpulkan bahwa sampel barang bukti tablet merah merupakan psikotropika golongan 1 yaitu ekstasi/ MDMA.
\end{abstract}

Kata-kata kunci: ekstasi; GCMS; MDMA (3,4-Methilendioxymethamphetamine); tes warna

\section{PENDAHULUAN}

Lebih dari satu dekade, globalisasi pasar obat-obatan terlarang atau narkoba terus meningkat baik dalam jumlahnya maupun keanekaragamannya (Crime et al., 2014). Secara umum, obat yang paling banyak digunakan adalah ganja (38\%), heroin (28\%) dan kokain (24\%), sedangkan dalam kehidupan malam atau diskotik yang paling populer penggunaannya yaitu 3,4-metilenedioxymethamphetamine (MDMA/ ekstasi) (Bershad et al., 2016) karena MDMA bertindak sebagai agonis monoaminergik yang tidak langsung melepaskan serotonin (5-hydroxytryptamine; 5-HT), norepinefrin dan dopamin melalui interaksi membran transport (Boxler et al., 2018). Oleh karena itu MDMA/ ekstasi banyak digunakan dikalangan masyarakat terutama remaja.

MDMA atau sering dikenal ekstasi merupakan senyawa turunan amfetamin yang dapat menyebabkan rasa senang berlebihan dan biasanya banyak digunakan pada festival musik dansa atau diskotik (Araújo et al., 2018). Sebagian besar ekstasi (MDMA) diproduksi secara sembunyi-sembunyi melalui aminasi reduktif dari 3,4 methylenedioxyphenyl-2-propanone (MDP-2-P) dengan methylamine (Collins et al., 2017). Adapun karakteristik ekstasi (MDMA) yaitu berbentuk tablet bergaris atau tidak bergaris, bersifat rapuh dan mudah hancur, serta memiliki berat kurang lebih 0,01mg (Mifsud et al., 2017). Penggunaan ekstasi (MDMA) dapat mempengaruhi resiko kesehatan yaitu dalam jangka pendek menyebabkan hipertermia, kejang, aritmia, hiponatremia, rhabdomiolisis dan kerusakan jangka panjang pada sistem saraf pusat (Araújo et al., 2018). Efek yang ditimbulkan bagi pengguna MDMA sangat berbahaya dan bahkan mampu menyebabkan kematian.

Karakteristik fisik dan kimia ekstasi (MDMA) telah dilakukan penelitian secara luas selama bertahuntahun (Budiartawan, dkk., 2014; Khajeamiri dkk., 2011;(Naether et al., 2008). Di Indonesia, identifikasi senyawa ini masih dilakukan secara kualitatif seperti penggunaan reagen marquis tetapi untuk metode analitik dalam menentukan kandungan suatu senyawa dalam tablet ekstasi dan memantau 
penyalahgunaannya obat ini masih belum dilakukan. Oleh karena itu diperlukan tindakan untuk mengindentifikasi suatu sampel tablet agar dapat diketahui kandungannya sehingga mengurangi penggunaan tablet ekstasi (MDMA). GCMS (Gas Chromatography-Mass Spectrometry) adalah instrumen yang paling sering digunakan untuk analisis sampel di bidang forensik. Dengan menggunakan waktu retensi dalam diagram identifikasi analit, maka dapat membandingkan senyawa yang belum diketahui dengan senyawa referensi sehingga mampu mengetahui kandungan senyawa dalam sampel (Kelly \& Bell, 2018).

Pada penelitian ini, penulis melakukan identifikasi barang bukti tablet menggunakan metode tes warna dan GCMS. Sampel tablet diperoleh dari penegak hukum POLDA DIY (Daerah Istimewa Yogyakarta) yang melakukan penyitaan di masyarakat. Tujuan dari penelitian ini yaitu untuk mengidentifikasi barang bukti tablet yang diduga ekstasi (MDMA) menggunakan metode tes warna dan GCMS. Identifikasi ini sangat penting bagi petugas penegak hukum dan staf layanan darurat sebagai upaya pengurangan penggunaan narkoba (Deconinck et al., 2019). Metode yang digunakan untuk analisis pendahuluan atau uji screening yaitu dengan mengamati perubahan warna secara kualitatif menggunakan reagent marquis (Fasich, 1999), (Couchman et al., 2019); (Graziano et al., 2019). Sedangkan metode GCMS digunakan untuk uji konfirmatif yaitu analisis yang didasarkan pada pemisahan kandungan senyawa-senyawa yang mudah menguap dan diinterpretasikan dalam bentuk kromatogram. Sehingga dapat diketahui kandungan senyawa yang ada dalam barang bukti tablet tersebut.

\section{EKSPERIMEN}

\section{Alat dan Bahan}

Percobaan ini dilakukan di Laboratorium Forensik POLRI Semarang. Adapun bahan-bahan yang digunakan yaitu sampel barang bukti tablet yang diperoleh dari POLDA Daerah Istimewa Yogyakarta, asam sulfat 95-97\% Merck, formaldehid min.37\% Merck dan metanol (Merck).

\section{Prosedur Kerja}

Penelitian identifikasi barang bukti tablet yang diduga ekstasi (MDMA) dilakukan dengan metode tes warna dan metode Gas Chromatography-Mass Spectroscopy (GC-MS). Dalam metode tes warna, serbuk tablet ditetesi 1-2 tetes reagen marquis. Reagen marquis dibuat dengan menambahkan $5 \mathrm{~mL}$ asam sulfat 95$97 \%$ dan 5 tetes formaldehid min.37\%. Setelah itu diamati perubahan warna yang terjadi. Hasil positif pada uji tes warna senyawa MDMA adalah adanya perubahan warna menjadi hitam atau ungu.

Selanjutnya dilakukan analisis menggunakan metode GCMS. Analisis menggunakan GCMS dilakukan dengan melarutkan serbuk tablet dengan $2 \mathrm{~mL}$ metanol murni pro analysis (Merck). Kemudian disentrifugasi selama 5 menit dengan kecepatan $1.800 \mathrm{rpm}$. Setelah itu dilakukan analisis menggunakan GC-MS dengan menginjekkan pada instrumen GCMS.

Adapun kondisi awal instrumen GCMS yang digunakan yaitu jenis kolom GC HP-5 dengan panjang $30 \mathrm{~m}$ dan diameter dalam $0,25 \mathrm{~mm}$. Lalu pada inletnya temperatur injektor sebesar $250^{\circ} \mathrm{C}$, dengan gas pembawa yaitu helium dan laju alir sebesar $2 \mathrm{~mL}^{\text {menit }}{ }^{-1}$. Kondisi elusi menggunakan thermal gradient dengan suhu awal $50^{\circ} \mathrm{C}$ dan kenaikan suhu setiap 5 menit naik $15^{\circ} \mathrm{C}$ sampai suhu $300^{\circ} \mathrm{C}$. Detektor yang digunakan adalah mass selective detector (MS).

Sedangkan pada kondisi MS digunakan energi ionisasi $70 \mathrm{eV}$, temperatur sumber ion $230^{\circ} \mathrm{C}$ dan mass scan range antara 30-550 amu. Setelah itu, dilakukan analisis hasil spektra yang telah didapatkan menggunakan data base library W10N11.

\section{HASIL DAN DISKUSI}

\section{Analisis Barang Bukti Tablet Menggunakan Tes Warna}

Gambar hasil percobaan dengan metode tes warna disajikan pada Gambar 1. 


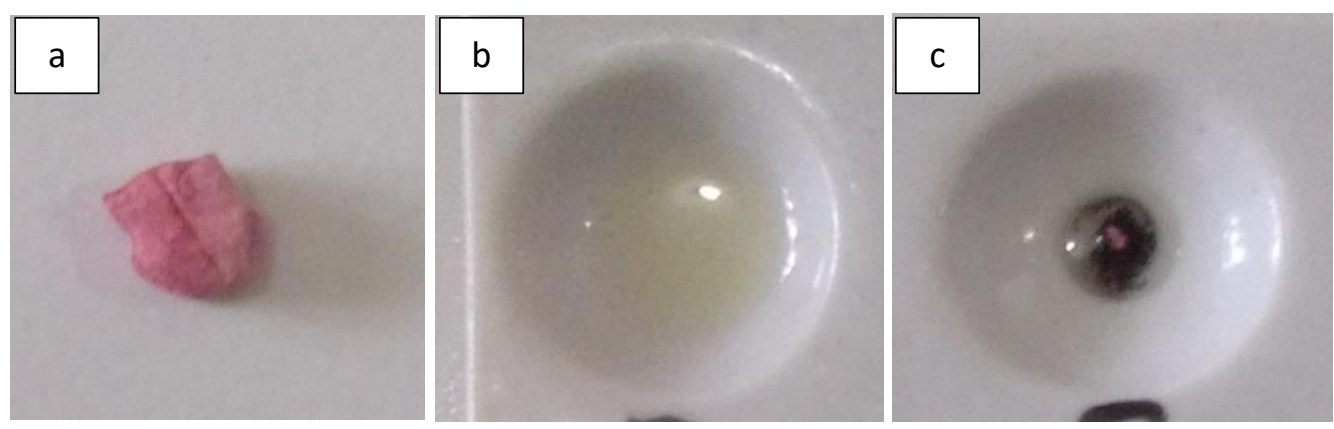

Gambar 1. Analisis Tes Warna (a) Sampel Tablet (b) Reagen Marquis (c) Serbuk sampel tablet dengan reagen marquis

Gambar 1a merupakan sampel barang bukti tablet yang akan dianalisis. Gambar $\mathbf{1 b}$ yaitu reagen marquis sebagai pembanding. Gambar 1c yaitu serbuk tablet yang ditambahkan dengan reagen marquis. Hasil yang diperoleh yaitu terjadi perubahan warna dari merah menjadi hitam. Hasil ini sesuai dengan percobaan yang dilakukan (Khajeamiri, 2016) dan (Khajeamiri et al., 2011) dikarenakan adanya reaksi kompleks antara reagen marquis yaitu dari ion formaldehid dan asam sulfat dengan senyawa aromatik pada senyawa 3,4 metilendioksimetamphetamine (MDMA) yang terdiri dari cincin benzena dan metilen dioksi. Berikut merupakan reaksi reagen marquis dengan MDMA:<smiles>[R]c1ccc2c(c1)OCO2</smiles><smiles>[R]C1=CC2=C(CC1Cc1cc3c(cc1[R])OCO3)OCO2</smiles>

Gambar 2. Reaksi Reagen Marquis dengan MDMA (Zakiyah, 2018)

Berdasarkan reaksi pada Gambar 2, ion karbonium dari formaldehid bereaksi dengan struktur aromatik dari senyawa sampel yaitu tablet. Ion karbonium distabilkan melalui rekasi dengan molekul kedua dari komponen aromatik pada suasana asam oleh asam sulfat. Adanya asam sulfat yang bersifat oksidator maka akan menyebabkan oksidasi, sehingga terbentuk kompleks. Oleh karena itu, akan dihasilkan ion karbonium yang berwarna ungu kehitaman.

\section{Analisis Barang Bukti Tablet Menggunakan Metode GCMS}

Hasil spektra GC pada Gambar 3 menunjukkan adanya dua puncak yang berarti ada dua senyawa yang terkandung dalam tablet. Puncak yang pertama yaitu senyawa 3,4-Metilendioksimetamphetamine (MDMA) dengan waktu retensi 10,875 menit. Hasil ini sesuai dengan Library W10N11 dengan tingkat kemiripan 93\%. Puncak yang kedua yaitu senyawa kafein dengan waktu retensi 13,341 menit yang sesuai dengan Library W10N11 dengan tingkat kemiripan 98\%. Senyawa-senyawa yang terkandung dalam sampel 
yang telah melewati detektor akan diteruskan menuju sistem masukan pada MS. Gambar 4 merupakan hasil spektra MS senyawa 3,4-Methylendioxymethamphetamine (MDMA).

Gambar 4 menunjukkan spektra MS dari senyawa aktif 3,4-Metilendioksimetamphetamine (MDMA). Berdasarkan gambar tersebut dapat diketahui bahwa senyawa MDMA memiliki pola fragmentasi pada puncak-puncak m/z 193,1; 178,1; 163,1; 148,1; 135,1; 120,1; 105,1; 91,1; 77,1; dan 58,1. Puncak paling tinggi yaitu pada $\mathrm{m} / \mathrm{z} 58,1$ yang disebut sebagai base peak dan biasanya dinilai $100 \%$ dibandingkan tinggi puncak yang lain. Sedangkan puncak yang paling kanan merupakan senyawa 3,4-metilendiokimetampetamin atau MDMA sebagai ion terberat yang disebut sebagai ion molekul. Pola fragmentasi yang terjadi dapat dilihat pada Gambar 5.

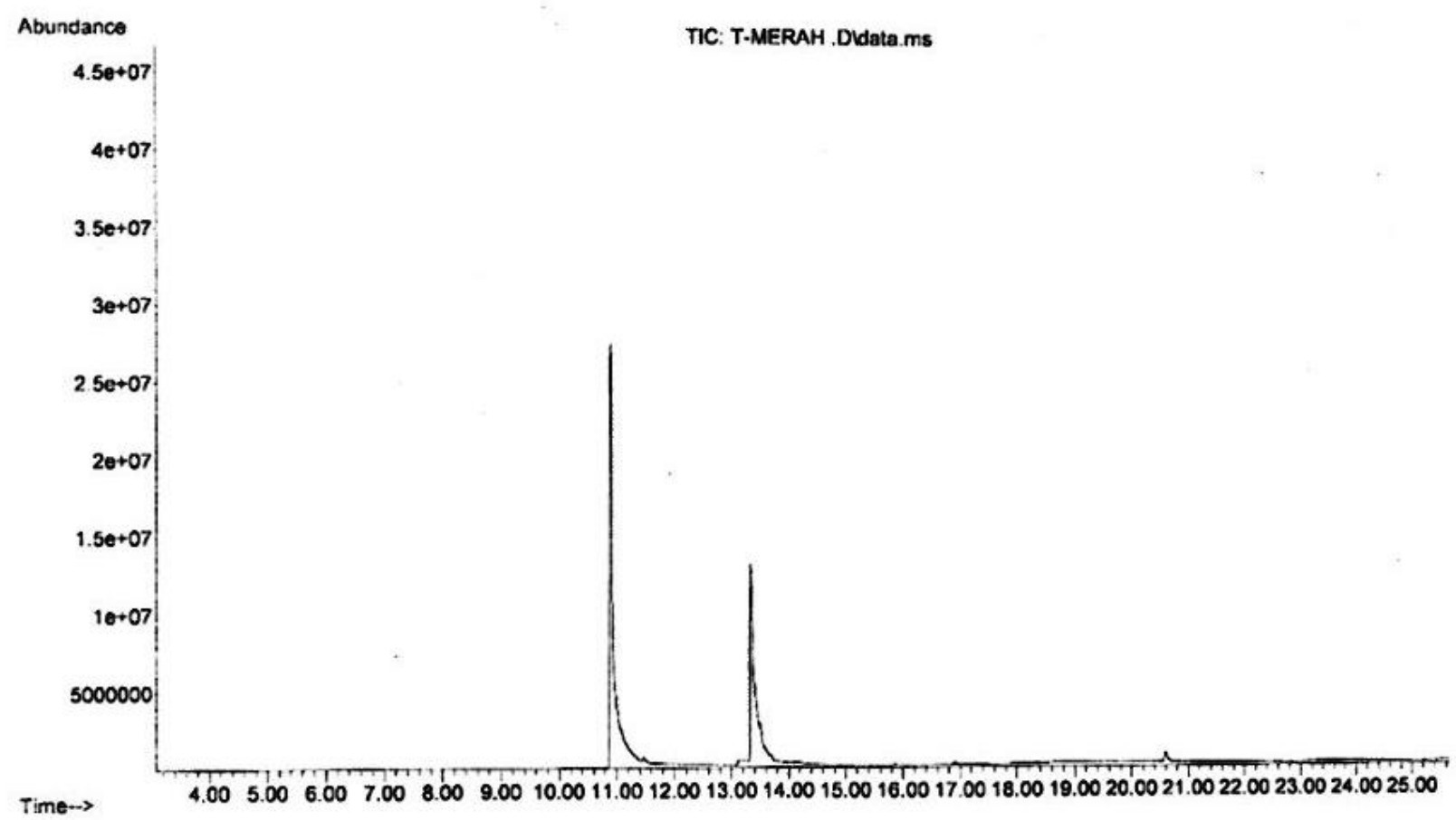

Gambar 3. Spektra GC Barang Bukti Tablet.

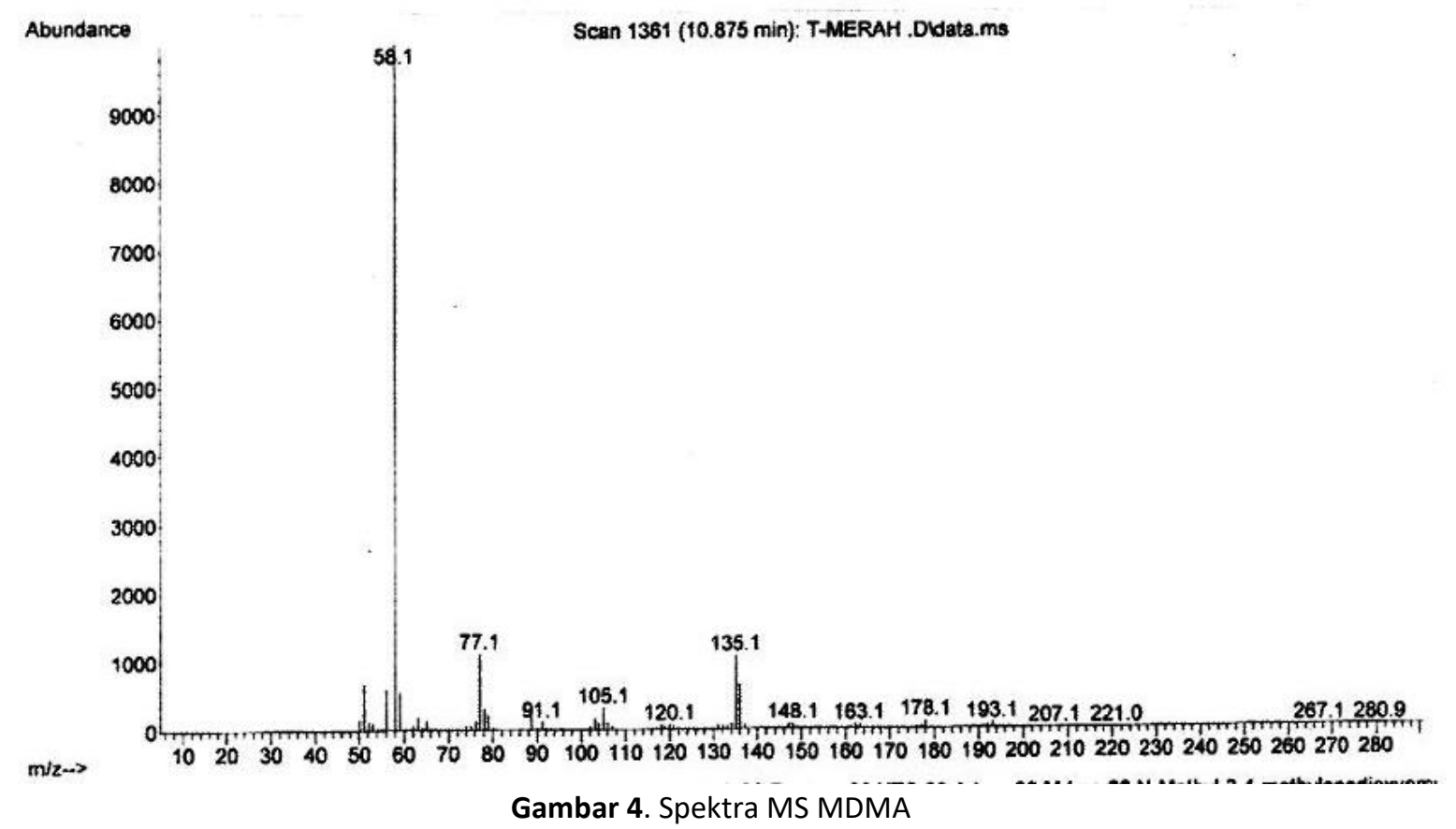


Jurnal Sains dan Edukasi Sains, Vol.3, No.2, Agustus 2020: 38-45<smiles></smiles>

$(58 \mathrm{~m} / \mathrm{z})$<smiles>CNC(C)Cc1ccc2c(c1)OCO2</smiles>

$(193 \mathrm{~m} / \mathrm{z})$

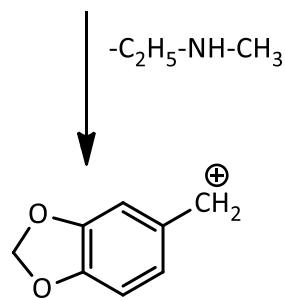

$(135 \mathrm{~m} / \mathrm{z})$
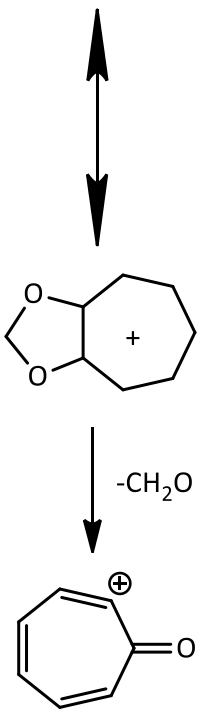

$(105 \mathrm{~m} / \mathrm{z})$<smiles>C[C](N)Cc1ccc2c(c1)OCO2</smiles>

$(178 \mathrm{~m} / \mathrm{z})$<smiles>C[C+]Cc1ccc2c(c1)OCO2</smiles>

$(163 \mathrm{~m} / \mathrm{z})$

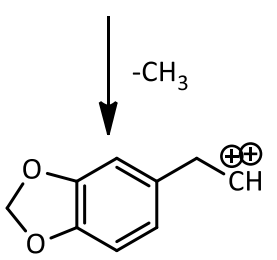

$(148 \mathrm{~m} / \mathrm{z})$<smiles>CCCCCC1=CC(=O)C(=O)C=C1</smiles>

$(120 \mathrm{~m} / \mathrm{z})$

Gambar 5. Pola Fragmentasi MDMA (Pham et al., 2013); (Liu et al., 2017)

Gambar 5 menunjukkan pola fragmentasi senyawa MDMA. Ion yang paling stabil akan memiliki kelimpahan paling besar. Pada fragmentasi di atas, ion Dimetiletanamin pada $\mathrm{m} / \mathrm{z}$ 58,1 memiliki kestabilan paling tinggi, sehingga kelimpahannya paling besar.

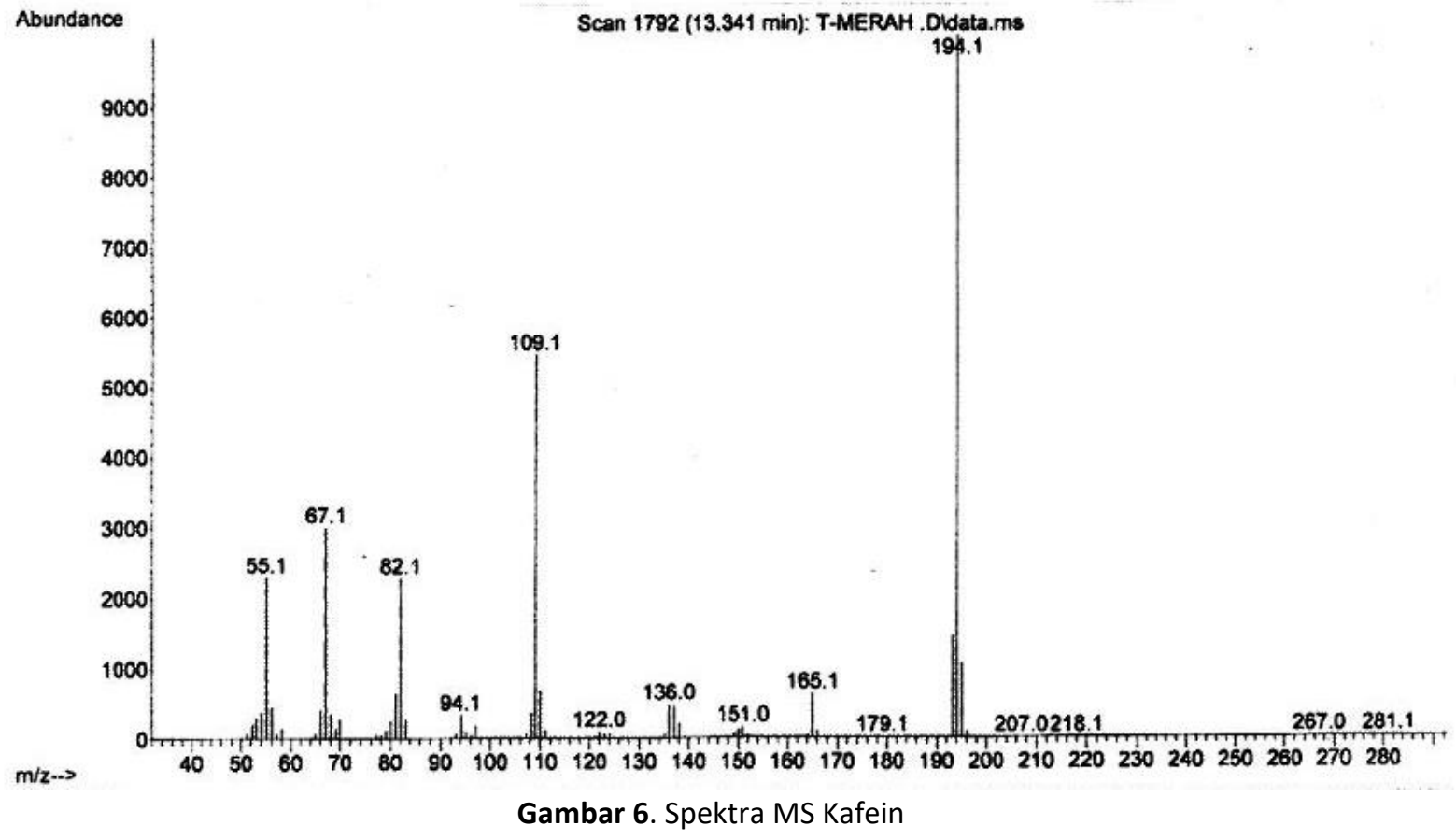


Gambar 6 merupakan spektra MS dari senyawa kafein. Ditinjau dari Mass Hunter Library W10N11 senyawa ini memiliki tingkat kemiripan $98 \%$ yang menunjukkan pola fragmentasi pada puncak-puncak $\mathrm{m} / \mathrm{z}$ 194,$1 ; 179,1 ; 165,1 ; 151,0 ; 136,0 ; 122,0 ; 109,1 ; 94,1 ; 82,1 ; 67,1 ;$ dan 55,1. Puncak yang paling tinggi yaitu pada $\mathrm{m} / \mathrm{z} 194,1$ yang disebut sebagai base peak dan biasanya dinilai $100 \%$ dibandingkan tinggi puncak yang lain. Tinggi puncak yang lain diukur realtif terhadap puncak ini. Puncak dasar atau base peak ini menunjukkan bahwa pada molekul ini memiliki kestabilan paling tinggi sehingga kelimpahannya paling besar. Sedangakan puncak yang paling kanan merupakan senyawa kafein yang menunjukkan berat molekul senyawa kafein sebagai ion terberat yang disebut sebagai ion molekul. Berikut merupakan gambar pola fragmentasi dari senyawa kafein:<smiles>Cc1nc2c([nH]1)c(=O)n(C)c(=O)n2C</smiles>

$(179 \mathrm{~m} / \mathrm{z})$

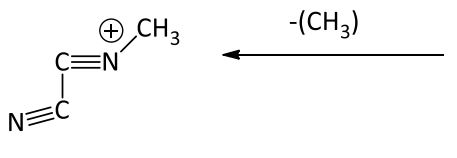

$(67 \mathrm{~m} / \mathrm{z})$<smiles>Cn1c(=O)c2c(ncn2C)n(C)c1=O</smiles><smiles>CN=C1N=CN(C)[C@H]1C=O</smiles>

$(136 \mathrm{~m} / \mathrm{z})$<smiles>[CH-]C=O</smiles><smiles>Cn1cnc2c1n(C)c(=O)n2C</smiles>

$(165 \mathrm{~m} / \mathrm{z})$<smiles>Cn1c(=O)n(C)c2[nH]cnc21</smiles>

$(151 \mathrm{~m} / \mathrm{z})$<smiles>CN=C1N=CNC1C=O</smiles>

$(122 \mathrm{~m} / \mathrm{z})$<smiles>CC(C)(C)C</smiles>
$(109 \mathrm{~m} / \mathrm{z})$<smiles>Cn1cnc(=N)[cH-]1</smiles><smiles>[3H][13CH]=O</smiles><smiles>C#CCCCCC</smiles><smiles>[CH2]N=C1C=NC=N1</smiles><smiles>CN=CC=NC</smiles>

$(82 \mathrm{~m} / \mathrm{z})$

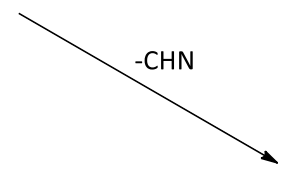

(55 m/z)

Gambar 7. Pola Fragmentasi Senyawa Kafein (Sierakowska et al., 2018)

Gambar 7 merupakan pola fragmentasi dari senyawa kafein. Senyawa yang paling stabil yaitu ion molekul kafein dengan m/z 194 sehingga kelimpahannya paling besar. 


\section{KESIMPULAN}

Berdasarkan data yang diperoleh dari kromatogram, baik spektra GC maupun spektra MS dapat disimpulkan bahwa sampel barang bukti tablet tersebut terbukti merupakan narkoba jenis ekstasi karena adanya kandungan senyawa aktif 3,4-methylenedioxymethamphetamine atau MDMA. Selain itu, juga mengandung kafein yang diduga tablet merah tersebut merupakan ekstasi campuran.

Sampel tablet terbukti merupakan psikotropika golongan 1 yaitu ekstasi dengan hasil analisis menggunakan GCMS terdapat dua puncak yaitu senyawa MDMA dan kafein dengan waktu retensi berturutturut yaitu 10,875 menit dan 13,341 menit. Hasil ini sesuai dengan Library W10N11 dengan tingkat kemiripan 93\% untuk senyawa MDMA dan 98\% untuk senyawa kafein.

\section{DAFTAR PUSTAKA}

Araújo, A. M., de Lourdes Bastos, M., Fernandes, E., Carvalho, F., Carvalho, M., \& de Pinho, P. G. (2018). GCMS metabolomics reveals disturbed metabolic pathways in primary mouse hepatocytes exposed to subtoxic levels of 3, 4-methylenedioxymethamphetamine (MDMA). Archives of Toxicology, 92(11), 3307-3323.

Bershad, A. K., Miller, M. A., Baggott, M. J., \& de Wit, H. (2016). The effects of MDMA on socio-emotional processing: Does MDMA differ from other stimulants? Journal of Psychopharmacology, 30(12), 12481258.

Boxler, M. I., Streun, G. L., Liechti, M. E., Schmid, Y., Kraemer, T., \& Steuer, A. E. (2018). Human metabolome changes after a single dose of 3, 4-methylenedioxymethamphetamine (MDMA) with special focus on steroid metabolism and inflammation processes. Journal of Proteome Research, 17(8), 2900-2907.

Budiartawan, I. G., Suaniti, N. M., \& Wirasuta, I. M. A. G. (n.d.). Profiling Fisik dan Kimia Tablet Ekstasi yang Beredar di Wilayah Polda Bali dengan Htptlc-densitometri dalam USAha Merunut Jalur Peredarannya. Indonesian Journal of Legal and Forensic Sciences, 4, 282189.

Collins, M., Donnelly, C., Cameron, S., Tahtouh, M., \& Salouros, H. (2017). Identification and characterization of N-tert-butoxycarbonyl-MDMA: a new MDMA precursor. Drug Testing and Analysis, 9(3), 399-404.

Couchman, L., Frinculescu, A., Sobreira, C., Shine, T., Ramsey, J., Hecht, M., Kipper, K., Holt, D., \& Johnston, A. (2019). Variability in content and dissolution profiles of MDMA tablets collected in the UK between 2001 and 2018-A potential risk to users? Drug Testing and Analysis, 11(8), 1172-1182.

Crime, U. N. O. on D. and, Ctr, V. I., \& Austria. (2014). Global Synthetic Drugs Assessment 2014 Amphetaminetype Stimulants and New Psychoactive Substances.

Deconinck, E., Van Campenhout, R., Aouadi, C., Canfyn, M., Bothy, J. L., Gremeaux, L., Blanckaert, P., \& Courselle, P. (2019). Combining attenuated total reflectance-infrared spectroscopy and chemometrics for the identification and the dosage estimation of MDMA tablets. Talanta, 195, 142151.

Fasich, D. (1999). Biotransformasi MDMA (Ecstasy) Studi Pada Penyalahgunaan Ecstasy.

Graziano, S., Anzillotti, L., Mannocchi, G., Pichini, S., \& Busardò, F. P. (2019). Screening methods for rapid determination of new psychoactive substances (NPS) in conventional and non-conventional biological matrices. Journal of Pharmaceutical and Biomedical Analysis, 163, 170-179.

Kelly, K., \& Bell, S. (2018). Evaluation of the reproducibility and repeatability of GCMS retention indices and mass spectra of novel psychoactive substances. Forensic Chemistry, 7, 10-18.

Khajeamiri, A. R. (2016). Rapid Identification of Ecstasy (MDMA) and Methamphetamine by Color Tests. Journal of Police Medicine, 5(1), 79-86. 
Khajeamiri, A. R., Kobarfard, F., Ahmadkhaniha, R., \& Mostashari, G. (2011). Profiling of ecstasy tablets seized in Iran. Iranian Journal of Pharmaceutical Research: IJPR, 10(2), 211.

Liu, C., Jia, W., Qian, Z., Li, T., \& Hua, Z. (2017). Identification of five substituted phenethylamine derivatives 5-MAPDB, 5-AEDB, MDMA methylene homolog, 6-Br-MDMA, and 5-APB-NBOMe. Drug Testing and Analysis, 9(2), 199-207.

Mifsud, M., Jickellsb, S., Mifsudc, J., \& Wolffd, K. (2017). 14 “Ecstasy"Tablets: Batch Matching for Forensic Drug Intelligence Purposes in Malta. Detection of Drug Misuse: Biomarkers, Analytical Advances and Interpretation, 288.

Naether, S., Buck, U., Bernhard, W., Zingg, C., \& Thali, M. J. (2008). Non-contact documentation of physical characteristics of ecstasy tablets, hemp coins, and imprint punches by using 3D optical surface scanning. Canadian Society of Forensic Science Journal, 41(4), 191-198.

Pham, A. Q. N., Kelly, T., \& Fu, S. (2013). Urine adulteration: can bleach be used to mask MDMA use? Analytical Methods, 5(16), 3948-3955.

Sierakowska, A., Jasiewicz, B., \& Pospieszny, T. (2018). Mass Spectrometry Study of New Polyamine Derivatives of Caffeine. Acta Chimica Slovenica, 65(4), 795-800.

Zakiyah, R. (2018). Analisis Senyawa 3,4 Methylenedioxymethamphetamine (MDMA) Dalam Sampel Barang Bukti Tablet Diduga Ekstasi Dengan Metode GC-MS Di Laboratorium Forensik Polri Cabang Semarang. Universitas Diponegoro 